\title{
The neurological ecology of fear: insights neuroscientists and ecologists have to offer one another
}

\section{Michael Clinchy ${ }^{*}$, Jay Schulkin ${ }^{2}$, Liana Y. Zanette ${ }^{3}$, Michael J. Sheriff $^{4}$, Patrick O. McGowan ${ }^{5}$ and Rudy Boonstra ${ }^{5}$}

\author{
1 Department of Biology, University of Victoria, Victoria, BC, Canada \\ 2 Department of Neuroscience, Georgetown University, Washington, DC, USA \\ ${ }^{3}$ Department of Biology, University of Western Ontario, London, ON, Canada \\ ${ }^{4}$ Institute of Arctic Biology, University of Alaska Fairbanks, Fairbanks, AK, USA \\ ${ }^{5}$ Centre for the Neurobiology of Stress, University of Toronto at Scarborough, Toronto, ON, Canada
}

\section{Edited by:}

Luke R. Johnson, Uniformed Services University of the Health Sciences, USA

\section{Reviewed by:}

Luke R. Johnson, Uniformed Services University of the Health Sciences, USA June-Seek Choi, Korea University, South Korea

${ }^{*}$ Correspondence:

Michael Clinchy, Department of Biology, University of Victoria, PO Box 3020 STN CSC, Victoria, BC, Canada V8W 3 N5.

e-mail:mclinchy@uvic.ca
That the fear and stress of life-threatening experiences can leave an indelible trace on the brain is most clearly exemplified by post-traumatic stress disorder (PTSD). Many researchers studying the animal model of PTSD have adopted utilizing exposure to a predator as a lifethreatening psychological stressor, to emulate the experience in humans, and the resulting body of literature has demonstrated numerous long-lasting neurological effects paralleling those in PTSD patients. Even though much more extreme, predator-induced fear and stress in animals in the wild was, until the 1990s, not thought to have any lasting effects, whereas recent experiments have demonstrated that the effects on free-living animals are sufficiently longlasting to even affect reproduction, though the lasting neurological effects remain unexplored. We suggest neuroscientists and ecologists both have much to gain from collaborating in studying the neurological effects of predatorinduced fear and stress in animals in the wild. We outline the approaches taken in the lab that appear most readily translatable to the field, and detail the advantages that studying animals in the wild can offer researchers investigating the "predator model of PTSD."

Keywords: animal model of PTSD, indirect predator effects, post-traumatic stress disorder, predation risk, predator stress

\section{INTRODUCTION}

Post-traumatic stress disorder (PTSD) represents arguably the most salient example of how fear and stress shape the mind. Because controlled prospective studies cannot be conducted on humans, it is necessary to use an "animal model" to help elucidate the etiology of PTSD and explore the associated neurological changes (Cohen et al., 2010). A suitable animal model should utilize stressors that emulate as closely as possible the relevant stressors in humans; the behavioral, physiological, and neurological responses elicited in the animal must reflect clinical symptomatology; and pharmacological agents known to affect symptoms in human patients should correct, with equal efficacy, comparable symptoms in the animal (Rosen and Schulkin, 1998; Roseboom et al., 2007; Stam, 2007; Armario et al., 2008; Masini et al., 2009; Mitra et al., 2009; Cohen et al., 2010).

Many researchers have adopted utilizing exposure to a predator (e.g., showing a rat a cat; Adamec and Shallow, 1993), or predator odor, as a stressor, in exploring the animal model of PTSD (Cohen et al., 2010; Mackenzie et al., 2010). Predator exposure was initially seized upon for practical reasons as this permits the researcher to utilize a (1) psychological stressor, that is (2) life-threatening, but (3) does not involve pain; all consistent with the etiology of PTSD in humans (Adamec and Shallow, 1993; Roseboom et al., 2007; Campeau et al., 2008; Takahashi et al., 2008; Staples et al., 2009; Cohen et al., 2010; Mackenzie et al., 2010). Of greatest importance with respect to understanding PTSD, the hallmark of which is the long-lasting or "transformational" change in the patient in response to a trauma (Yehuda and Bierer, 2009), predator exposure has been demonstrated to have long-lasting effects on: anxiety-like behaviors, glucocorticoid levels, dendritic morphology, gene expression, and the release of the neuropeptide corticotrophin-releasing hormone $(\mathrm{CRH})$ in the amygdala (the region of the brain most frequently linked to fear), as well as many other phenomena associated with PTSD (Adamec and Shallow, 1993; Schulkin et al., 2005; Roseboom et al., 2007; Stam, 2007; Armario et al., 2008; Campeau et al., 2008; Rosen et al., 2008; Takahashi et al., 2008; Masini et al., 2009; Mitra et al., 2009; Staples et al., 2009). Predator exposure early in life has also been shown to increase vulnerability to developing subsequent long-term behavioral disruptions when exposed to a predator in adulthood (Cohen et al., 2006), consistent with the growing evidence that individual variation in susceptibility to PTSD is influenced by early-life experiences (Yehuda and Bierer, 2009).

Researchers studying the "predator model of PTSD" have increasingly begun to suggest that predator exposure offers an additional advantage in attempting to understand PTSD, because long-lasting predator-induced fear and stress is ethologically and ecologically relevant, and represents a valid experience applicable to animals in their natural environment (Roseboom et al., 2007; Cantor, 2009; Staples et al., 2009; Cohen et al., 2010). Independently, wildlife ecologists have begun to arrive at a similar conclusion, following a line of inquiry that began in the 1990s (Creel and Christianson, 2008). Traditionally, the view of both wildlife ecologists and comparative endocrinologists has been that 
predator-induced fear and stress is necessarily acute and transitory: the prey detects a predator; freezes, flees, or fights; survives or does not; the event is over; the animal returns to going about its business; homeostasis is restored (Schulkin, 2003; Sheriff et al., 2009). According to this traditional view, lasting effects are necessarily maladaptive and pathological: since the evolutionary "function" of predator-induced fear and stress is to ensure immediate survival, any further or lasting effect on fitness (i.e., Darwinian fitness), such as an effect on subsequent reproduction, must be maladaptive; and since the "function" of the stress axis is to maintain homeostasis, chronic stress must be pathological (Lupien et al., 2009; Rodrigues et al., 2009; Sheriff et al., 2009). Given this traditional view, the many lasting effects of predator exposure documented by researchers exploring the predator model of PTSD must be an artifact. The most parsimonious explanation being - given this perspective - that such lasting effects stem from the unnatural conditions of captivity, i.e., it is not the fact of predator exposure but the fact the predator is inescapable that must explain these effects, since the animal cannot flee from the predator as it naturally would (Creel et al., 2009; Jöngren et al., 2010).

We propose that the traditional view in wildlife ecology and comparative endocrinology, that the effects of predators on freeliving animals are necessarily transitory, is no longer tenable, since the results from a growing number of experimental and observational field studies show that predator-induced fear and stress has long-lasting effects on animals in the wild (Creel and Christianson, 2008; Hawlena and Schmitz, 2010), comparable to those documented by investigators addressing the predator model of PTSD. For animals in the wild that are in peril every moment of every day of being torn limb from limb by any number of predators, responses resembling PTSD in humans may result from necessary trade-offs to stay alive, that are fully adaptive, because dead animals do not reproduce. We suggest that for both, researchers studying the predator model of PTSD, and ecologists, conducting collaborative studies on predator-induced fear and stress on animals in the wild would be of enormous benefit. For investigators addressing the predator model of PTSD, the extremity of the stressors faced by animals in the wild, in a real world context, would appear to much better emulate the circumstances leading to PTSD in humans. For ecologists, building upon the progress that has been made in understanding PTSD in the lab provides the most expedient means of addressing the mechanisms underlying predator-induced fear and stress effects in the field. We briefly review approaches taken to studying PTSD in the lab that appear translatable to the field; and then describe recent field studies on songbirds and snowshoe hares showing that, predator-induced fear and stress affects reproduction in animals in the wild, and the physiological responses involved appear comparable to those documented in response to predator exposure in the lab.

\section{APPROACHES TRANSLATABLE TO THE FIELD}

Behavioral responses to predator exposure in the lab include avoidance, reduced activity and increased vigilance (Blanchard and Blanchard, 1989; Stam, 2007; Armario et al., 2008; Takahashi et al., 2008), and similar responses to predator exposure have been exhaustively documented in the field since at least Darwin's time (Caro, 2005). Predator exposure in the lab results in changes in plasma glucocorticoid levels (Blanchard et al., 1998; Roseboom et al., 2007; Takahashi et al., 2008; Masini et al., 2009) and the same has been shown in both birds and mammals in the field (Hawlena and Schmitz, 2010). Measuring glucocorticoid metabolites in feces provides a new, non-invasive means of assessing glucocorticoid responses to predator exposure that is particularly useful in field studies (Sheriff et al., 2009, 2010).

Studying the neurological effects of predator-induced fear and stress in animals in the wild will likely rely primarily on destructive sampling. Though effects on live animals could be studied using pharmacological methods or neuroimaging, there are practical difficulties translating these approaches to the field. The suitability of using predator exposure in exploring the animal model of PTSD has been validated, in part, by the numerous studies showing that pharmacological agents known to affect symptoms of PTSD in human patients also correct comparable symptoms in animals exposed to predators (Cohen et al., 2006, 2010; Stam, 2007; Armario et al., 2008; Nanda et al., 2008). Some of these pharmacological agents can be administered in food (e.g., antalarmin; Zoumakis et al., 2006; Armario et al., 2008), which is of practical advantage for use with free-living animals since it is then not necessary to capture the subject to administer the drug. The principal constraint on using pharmacological agents on animals in the wild is almost certain to be the cost of the drugs, since the intrinsically greater error variation associated with studying any phenomenon in the field necessitates a larger sample size than that required in the lab.

A number of recent neuroimaging studies using magnetic resonance imaging (MRI) have evaluated the neurological effects of exposure to predator odor in lab rats (e.g., Chen et al., 2007; Febo et al., 2009; Huang et al., 2011). MRI has also been used to assess neuroactivity in response to other stimuli in mice and songbirds (Van der Linden et al., 2007). Neuroimaging holds enormous promise as a technique for studying effects on animals in the wild because, being non-destructive, subjects could be returned to the field to determine if differences in brain activity predicted their subsequent behavior and reproduction. However, though MRI is non-destructive it is necessarily invasive and may be very injurious depending upon the method used (e.g., the manganese used in manganese-enhanced MRI is potentially toxic; Silva et al., 2004). At a minimum, neuroimaging requires restraining the subject's head in a scanner for a protracted period. To measure effects in conscious animals requires acclimation to being restrained in this manner, which takes several days in laboratory animals (King et al., 2005), and may be unachievable in many wild-caught animals. Even if anesthetized during the procedure, the trauma of capturing a wild animal and transporting it to wherever the scanner is might render the results uninterpretable (Van der Linden et al., 2007). Nonetheless, we strongly recommend that using neuroimaging to study effects on animals in the wild should at least be attempted.

Because animals in the wild are generally challenging to capture, and limited in number, it is critical to maximize the information extracted from every animal euthanized. Moreover, because freeliving animals must be captured, the conditions of capture will vary, meaning the rate at which tissue can be obtained will vary, and the circumstances will often be less than ideal. Measures that respond to an acute trauma or perturbation, such as the trauma of capture, will be largely unsuitable. Several new approaches to 
measuring neurological effects, developed in the lab, nonetheless appear amenable to use on animals in the wild, even given these constraints.

Immunohistochemistry has been used to map the expression of genes in response to predator exposure in various brain regions that appear central to the phenomenon of fear (such as the medial amygdala). Whereas a number of lab studies have mapped the expression of the immediate-early gene c-fos, in response to predator exposure (Dielenberg et al., 2001; Roseboom et al., 2007; Campeau et al., 2008), c-fos is rapidly expressed (within <1 h; Armario et al., 2008) and rapidly down-regulated (Staples et al., 2009), which is problematic for use in the field. Two recent studies (Staples et al., 2009; Mackenzie et al., 2010) have mapped the expression of fosB and its protein products $\mathrm{Fos} B / \Delta \mathrm{FosB}$, as an alternative to mapping c-fos. $\Delta$ FosB can persist in the brain for weeks after chronic stimulus exposure (McClung et al., 2004), and Staples et al. (2009) reported that FosB $/ \Delta$ FosB expression remained elevated 7 days after repeated predator exposure, making this a much more suitable marker for use in field studies.

Global gene expression has been assessed in response to predator exposure using cDNA microarrays (gene chips) in rats and chickens. Roseboom et al. (2007) euthanized rats $3 \mathrm{~h}$ after predator exposure, and found increased CRH-binding protein gene expression in the amygdala, consistent with previous studies (Schulkin et al., 2005). Jöngren et al. (2010) euthanized chickens 2 week after predator exposure and identified 13 significantly differentially expressed genes in the midbrain. Roseboom et al.'s (2007) findings confirm that cDNA microarrays can be used to identify the expression of genes expected to be upregulated in response to fear, and Jöngren et al.'s (2010) study shows that this approach can be used to detect long-lasting effects, even in non-mammalian subjects.

Quantifying dendritic morphology appears ideally suited for indentifying individual variation in susceptibility to predatorinduced fear and stress in field studies, and may be useful in evaluating predator-induced changes in neural architecture. Mitra et al. (2009) evaluated behavioral differences in subjects 2 weeks after predator exposure and found differences in the architecture of the neurons in the basolateral amygdala. Total dendritic length, dendritic extent, and total branch points were all greater in individuals that continued to demonstrate anxiety-like behaviors as compared to those that no longer showed anxietylike symptoms. Though the design of Mitra et al.'s (2009) study did not allow them to determine whether these differences in dendritic morphology were pre-existing or induced by predator exposure, Mitra and Sapolsky (2008) reported changes in dendritic morphology in response to a single day of stress, suggesting that predator-induced fear could indeed induce such changes in neural architecture.

Yehuda and Bierer (2009) recently reviewed the potential role of epigenetic changes in the etiology of individual differences in susceptibility to PTSD. Epigenetic modifications involve longlasting, often environmentally induced, changes in gene expression and function, that can be inter-generationally transmissible (i.e., heritable), though the DNA sequence itself remains unchanged (Champagne and Curley, 2009; Yehuda and Bierer, 2009). Several lines of evidence point to epigenetic changes as potentially being involved in predisposing individuals to PTSD, including the asso- ciation of PTSD risk with maternal PTSD, the relevance of childhood adversity to the development of PTSD, and recent evidence of a relationship between childhood abuse, DNA methylation (in gene promoters, an epigenetic marker of gene silencing) and suicide (McGowan et al., 2008, 2009; Yehuda and Bierer, 2009). As noted above, Cohen et al. (2006) reported that early-life predator exposure increased vulnerability to behavioral disruptions in response to exposure in adulthood, though there have been no studies looking specifically at predator-induced epigenetic changes. In the aforementioned suicide study, subjects had been dead an average of $24 \mathrm{~h}$ before sampling, suggesting that changes in DNA methylation ought to be detectable in the brains of animals in the wild collected under less than ideal field conditions, as recently corroborated by Pilsner et al. (2010) in a study that examined DNA methylation in the brains of polar bears shot by aboriginal hunters in eastern Greenland.

\section{FIELD STUDIES SHOWING LONG-LASTING EFFECTS OF PREDATOR EXPOSURE}

Evolutionarily, the "function" of staying alive is to reproduce, i.e., to transmit genes to the next generation. For ecologists, reproduction is the "currency" that matters. Ecological factors such as food and parasites, with obvious long-lasting effects (malnutrition and disease), have always been considered to be those most likely to affect reproduction, because reproduction (giving birth and rearing young) is a slow process. Traditionally, predators have not been thought to affect reproduction because predator-induced fear and stress has been considered to be far too acute and transitory. Behavioral (e.g., Kotler, 1992) and physiological (e.g., Boonstra et al., 1998) studies began, in the 1990s, to suggest that predatorinduced fear and stress could have lasting effects on animals in the wild, but because of the logistical challenges involved the critical experiments necessary to demonstrate effects on reproduction have only very recently been conducted. The principal challenge concerns space. Free-living animals can, and do, simply flee or avoid, a predator in a cage, predator models, or predator odor stations (e.g., Stankowich and Blumstein, 2005). Because sound travels, and thus occupies space, field studies often use playbacks of recorded predator calls and sounds to investigate effects of predator exposure. Moreover, for organisms that rely more on sound and sight than smell, such as birds and humans, auditory stimuli are generally more meaningful than olfactory ones (Jarvis, 2004), and acoustic cues may frequently be more alarming than visual ones (Cohen et al., 2010).

Only one study to date on a bird or a mammal has, to our knowledge, exposed free-living prey to increased predator cues in the field, and demonstrated a resulting effect on the number of offspring produced per year. Zanette et al. (submitted) used an array of speakers spaced over several hectares to expose nesting female song sparrows to playbacks of either predator calls and sounds, or non-threatening calls and sounds. Females exposed to elevated predation threat produced almost $40 \%$ fewer offspring than controls ( $3.8 \pm 0.4$ vs. $6.0 \pm 0.4$, mean $\pm \mathrm{SE}$ ), over the 4 -month breeding season, because they laid fewer eggs, fewer of their eggs hatched, and more of their chicks starved to death. These effects on reproduction were most likely mediated in part by predator-threat-induced changes in glucocorticoid levels, because work on the same study populations has 
demonstrated lasting effects on glucocorticoid levels associated with variation in predator abundance (Clinchy et al., 2004, 2011), and the probability of suffering nest predation (Travers et al., 2010).

Sheriff et al. (2009) recently reported correlative results suggesting that predator exposure affects glucocorticoid levels and reproduction in free-living snowshoe hares, consistent with the results from Zanette et al.'s (submitted) experiment. To corroborate their findings, Sheriff et al. (2009) presented a live predator (a trained dog) to pregnant hares housed in $4 \mathrm{~m} \times 4 \mathrm{~m}$ outdoor pens, and demonstrated that predator-exposed females had dramatically elevated fecal glucocorticoid metabolite (FCM) levels, and were significantly less likely to give birth to live young.

In a subsequent study on snowshoe hares, Sheriff et al. (2010) showed that predator exposure may have very long-lasting effects on animals in the wild, extending from one generation to the next. Sheriff et al. (2010) reported that at a population level, predator exposure, mean maternal FCM levels, and mean juvenile FCM levels, were all correlated, suggesting that predator-induced glucocorticoid changes in mother hares affect their offspring's glucocorticoid levels. To corroborate these findings, Sheriff et al. (2010) measured FCM levels in pregnant hares, housed in $4 \mathrm{~m} \times 4 \mathrm{~m}$ outdoor pens, and demonstrated that each mother's FCM level was highly correlated with her offspring's glucocorticoid responses to a hormonal challenge, when the latter was 28 days old. Thus, in animals in the wild, maternal or early-life exposure to predators may increase responsiveness to predators later in life, consistent with Cohen et al's (2006) lab results demonstrating that early-life predator exposure increases vulnerability to behavioral disruptions when exposed to a predator in adulthood.

Life-long maternal effects on the glucocorticoid responsiveness of their offspring, resembling the results shown by Sheriff et al. (2010), have been well-studied in relation to stress effects on maternal care in laboratory rodents, and have been shown to be associated with DNA methylation of genes affecting glucocorticoid receptor function in the hippocampus (Weaver et al., 2004; Kappeler and Meaney, 2010). In an example of the kind of collaboration between neuroscientists and ecologists we are herein hoping to encourage, McGowan and Boonstra are currently examining the brains of juvenile snowshoe hares, collected in the field, whose mothers were subject to naturally varying levels of predator exposure, to test if maternal predator exposure affects DNA methylation in their offspring's hippocampus in a manner similar to the way in which childhood abuse evidently affects DNA methylation in humans, as shown in the aforementioned suicide study (McGowan et al., 2008, 2009).

Calisi and Bentley (2009) recently proposed that studying neurobiology and behavior in semi-natural settings may provide a means to merge lab and field approaches. Our focus here is on the lasting effects of predator-induced fear and stress on neurobiology and ecology. As noted above, the principal challenge in studying such lasting ecological effects concerns space, and this applies equally to studying such effects in a semi-natural setting - the subject must have the same amount of space available as it would if it were free-living, to flee or avoid a predator, otherwise any effects seen could be attributed to the unnatural conditions of captivity (Creel et al., 2009). Sheriff et al's $(2009,2010)$ exposure of caged hares to a predator, for example, cannot be considered definitive, for this reason (Clinchy et al., 2011). Moreover, since, as noted above, the ecological "currency" that matters is reproduction, the subject must be able to reproduce as it naturally would. Very large (e.g., several hundred square meter) outdoor enclosures may fulfill these requirements when studying very small animals (e.g., mice or songbirds), whereas housing an animal in a somewhat larger cage than usual in an animal care building (e.g., Blanchard and Blanchard, 1989; Choi and Kim, 2010) does not meet these criteria.

The scope for future collaborations between neuroscientists and ecologists will almost certainly involve studying many more species than just sparrows and hares. As further field experiments on the effects of predator exposure on reproduction are conducted, we have no doubt such effects will be found to be common. Effects on components of reproductive success have already been documented in experiments on several other species. Eggers et al. (2006) reported effects of predator call playbacks on the number of eggs laid by Siberian jays, and Fontaine and Martin (2006) found that where predators were removed songbirds laid heavier eggs. Karels et al. (2000) similarly showed that where predators were removed the proportion of arctic ground squirrel females weaning young was increased. Lasting behavioral and physiological effects pointing to likely effects on reproduction have been shown in an even larger number of species (Creel and Christianson, 2008; Hawlena and Schmitz, 2010). What effect such predator-induced fear and stress has in shaping the minds of free-living birds and mammals is a question that is almost completely unexplored, presenting a wideopen field of study replete with opportunities for new discoveries.

\section{CONCLUSION}

Numerous laboratory experiments have shown that predatorinduced fear and stress has lasting neurological effects, and wildlife ecologists have begun demonstrating that predator-induced fear and stress has lasting effects on reproduction in free-living animals in the field. We propose that the next two critical questions to answer are: (1) whether predator-induced fear and stress has lasting neurological effects on free-living animals, and if so; (2) which of the effects seen in the lab appear most frequently in wild animals in the field. The insights neuroscientists have to offer ecologists in exploring the effects of predator-induced fear and stress on the minds of wild animals in the field include, where to begin, and what to measure. The insights ecologists, in turn, have to offer researchers studying the predator model of PTSD include, establishing which effects seen in the lab are observed in the greatest number of species and circumstances, and which are most biologically meaningful as gaged by their association with effects on reproduction. We suggest that if, as the predator model assumes, PTSD in humans has evolutionary precursors, then it is virtually certain that collaborations between neuroscientists and ecologists will greatly enhance our understanding of the etiology of PTSD and the associated neurological changes.

\section{ACKNOWLEDGMENTS}

We thank Tony D. Williams and John C. Wingfield for organizing a series of workshops, funded by the Natural Sciences and Engineering Research Council of Canada and the US National Science Foundation, which provided the impetus for this paper. We also thank two anonymous reviewers for their very helpful comments on an earlier draft. 


\section{REFERENCES}

Adamec, R. E., and Shallow, T. (1993). Lasting effects on rodent anxiety of a single exposure to a cat. Physiol. Behav. 54, 101-109.

Armario, A., Escorihuela, R. M., and Nadal, R. (2008). Long-term neuroendocrine and behavioural effects of a single exposure to stress in adult animals. Neurosci. Biobehav. Rev. 32, 1121-1135.

Blanchard, R. J., and Blanchard, D. C. (1989). Antipredator defensive behaviors in a visible burrow system. J. Comp. Psychol. 103, 70-82.

Blanchard, R. J., Nikulina, J. N., Sakai, R. R., McKittrick, C., McEwen, B., and Blanchard, D. C. (1998). Behavioral and endocrine change following chronic predatory stress. Physiol. Behav. 63, 561-569.

Boonstra, R., Hik, D., Singleton, G. R., and Tinnikov, A. (1998). The impact of predator-induced stress on the snowshoe hare cycle. Ecol. Monogr. 68, 371-394.

Calisi, R. M., and Bentley, G. E. (2009). Lab and field experiments: are they the same animal? Horm. Behav. 56, 1-10.

Campeau, S., Nyhuis, T. J., Sasse, S. K., Day, H. E. W., and Masini, C. V. (2008). Acute and chronic effects of ferret odor exposure in SpragueDawley rats. Neurosci. Biobehav. Rev. 32, 1277-1286.

Cantor, C. (2009). Post-traumatic stress disorder: evolutionary perspectives. Aust. N.Z. J. Psychiatry 43, 1038-1048.

Caro, T.M. (2005).Anti-Predator Defenses in Birds and Mammals. Chicago: University of Chicago Press.

Champagne, F.A., and Curley, J.P. (2009). Epigenetic mechanisms mediating the long-term effects of maternal care on development. Neurosci. Biobehav. Rev. 33, 593-600.

Chen, W., Tenney, J., Kulkarni, P., and King, J. A. (2007). Imaging unconditioned fear response with manganeseenhanced MRI (MEMRI).Neuroimage 37, 221-229.

Choi, J.-S., and Kim, J. J. (2010). Amygdala regulates risk of predation in rats foraging in a dynamic fear environment. Proc. Natl. Acad. Sci. U.S.A. 107, 21773-21777.

Clinchy, M., Zanette, L., Boonstra, R., Wingfield, J. C., and Smith, J. N. M. (2004). Balancing food and predator pressure induces chronic stress in songbirds. Proc. R. Soc. Lond. B Biol. Sci. 271, 2473-2479.

Clinchy, M., Zanette, L., Charlier, T. D., Newman, A. E. M., Schmidt, K. L., Boonstra, R., and Soma, K. K. (2011). Multiple measures elucidate glucocorticoid responses to environmental variation in predation threat. Oecologia. doi: 10.1007/s00442-011-1915-2. [Epub ahead of print].

Cohen, H., Kozlovsky, N., Richter-Levin, G., and Zohar, J. (2010). "Posttraumatic stress disorder in animal models," in Stress - From Molecules to Behaviour, eds H. Soreq, A. Friedman, and D. Kaufer (Weinheim: WileyVCH Verlag GmbH \& Co. KGaA), 263-282.

Cohen, H., Matar, M. A., Richter-Levin, G., and Zohar, J. (2006). The contribution of an animal model toward uncovering biological risk factors for PTSD. Ann. N. Y. Acad. Sci. 1071, 335-350.

Creel, S., and Christianson, D. (2008). Relationships between direct predation and risk effects. Trends Ecol. Evol. 23, 194-201.

Creel, S., Winnie, J.A. Jr., and Christianson, D. (2009). Glucocorticoid stress hormones and the effect of predation risk on elk reproduction. Proc. Natl. Acad. Sci. U.S.A. 106, 12388-12393.

Dielenberg, R. A., Hunt, G. E., and McGregor, I. S. (2001). 'When a rat smells a cat': the distribution of Fos immunoreactivity in rat brain following exposure to a predatory odor. Neuroscience 104, 1085-1097.

Eggers, S., Griesser, M., Nystrand, M. and Ekman, J. (2006). Predation risk induces changes in nest-site selection and clutch size in the Siberian jay. Proc. R. Soc. Lond. B Biol. Sci. 273, 701-706.

Febo, M., Shields, J., Ferris, C. F., and King, J. A. (2009). Oxytocin modulates unconditioned fear response in lactating dams: an fMRI study. Brain Res. 1302, 183-193.

Fontaine, J. J., and Martin, T. E. (2006). Parent birds assess nest predation risk and adjust their reproductive strategies. Ecol. Lett. 9, 428-434.

Hawlena, D., and Schmitz, O. J. (2010). Physiological stress as a fundamental mechanism linking predation to ecosystem functioning. Am. Nat. 176, 537-556.

Huang, W., Heffernan, M. E., Zhixin, L., Zhang, N., Overstreet, D. H., and King, J. A. (2011). Fear induced neuronal alterations in a genetic model of depression: an fMRI study on awake animals. Neurosci. Lett. 489, 74-78.

Jarvis, E. D. (2004). Learned birdsong and the neurobiology of human language. Ann. N. Y. Acad. Sci. 1016, 749-777.

Jöngren, M., Westander, J., Nätt, D., and Jensen, P. (2010). Brain gene expression in relation to fearfulness in female red junglefowl (Gallus gallus). Genes Brain Behav. 9, 751-758.

Kappeler, L., and Meaney, M. J. (2010). Epigenetics and parental effects. Bioessays 32, 818-827.
Karels, T. J., Byrom, A. E., Boonstra, R., and Krebs, C. J. (2000). The interactive effects of food and predators on reproduction and overwinter survival of arctic ground squirrels. J. Anim. Ecol. 69, 235-247.

King, J. A., Garelick, T. S., Brevard, M. E. Chen, W., Messenger, T. L., Duong, T. Q., and Ferris, C. F. (2005). Procedure for minimizing stress for fMRI studies in conscious rats. J. Neurosci. Methods 148, 154-160.

Kotler, B. P. (1992). Behavioral resource depression and decaying perceived risk of predation in two species of coexisting gerbils. Behav. Ecol. Sociobiol. 30 , 239-244.

Lupien, S. J., McEwen, B. S., Gunnar, M. R., and Heim, C. (2009). Effects of stress throughout the lifespan on the brain, behaviour and cognition. Nat. Rev. Neurosci. 10, 434-445.

Mackenzie, L., Nalivaiko, E., Beig, M. I. Day, T. A., and Walker F. R. (2010). Ability of predator odor exposure to elicit conditioned versus sensitised post traumatic stress disorderlike behaviours, and forebrain FosB expression, in rats. Neuroscience 169 733-742.

Masini, C. V., Sasse, S. K., Garcia, R. J., Nyhuis, T. J., Day, H. E. W., and Campeau, S. (2009). Disruption of neuroendocrine stress responses to acute ferret odor by medial, but not central amygdala lesions in rats. Brain Res. 1288, 79-87.

McClung, C. A., Ulery, P. G., Perrotti, L. I., Zachariou, V., Berton, O., and Nestler, E. J. (2004). $\Delta$ FosB: a molecular switch for long-term adaptation in the brain. Mol. Brain Res. 132, 146-154.

McGowan, P. O., Sasaki, A., D'Alessio, A. C., Dymov, S., Labonté, B., Szyf, M. Turecki, G., and Meaney, M. J. (2009). Epigenetic regulation of the glucocorticoid receptor in human brain associates with childhood abuse. Nat. Neurosci. 12, 342-348.

McGowan, P. O., Sasaki, A., Huang, T. C. T., Unterberger, A., Suderman, M. Ernst, C., Meaney, M. J., Turecki, G. and Szyf, M. (2008). Promoter-wide hypermethylation of the ribosomal RNA gene promoter in the suicide brain. PLOS ONE 3, e2085. doi: 10.1371/journal.pone.0002085

Mitra, R., Adamec, R., and Sapolsky, R. (2009). Resilience against predator stress and dendritic morphology of amygdala neurons. Behav. Brain Res. 205, 535-543.

Mitra, R., and Sapolsky, R. (2008). Acute corticosterone treatment is sufficient to induce anxiety and amygdaloid dendritic hypertrophy. Proc. Natl. Acad. Sci. U.S.A. 105, 5573-5578.
Nanda, S. A., Qi, C., Roseboom, P. H., and Kalin, N. H. (2008). Predator stress induces behavioral inhibition and amygdala somatostatin receptor 2 gene expression. Genes Brain Behav. 7, 639-648.

Pilsner, J. R., Lazarus, A. L., Nam, D.-H., Letcher, R. J., Sonne, C., Dietz, R., and Basu, N. (2010). Mercury-associated DNA hypomethylation in polar bear brains via the LUminometric Methylation Assay: a sensitive method to study epigenetics in wildlife. $\mathrm{Mol}$. Ecol. 19, 307-314.

Rodrigues, S. M., LeDoux, J. E., and Sapolsky, R. M. (2009). The influence of stress hormones on fear circuitry. Annu. Rev. Neurosci. 32, 289-313.

Roseboom, P.H., Nanda, S.A., Bakshi, V.P., Trentani,A., Newman, S.M., and Kalin, N. H. (2007). Predator threat induces behavioral inhibition, pituitaryadrenal activation and changes in amygdala CRF-binding protein gene expression. Psychoneuroendocrinology 32, 44-55.

Rosen, J. B., Pagani, J. H., Rolla, K. L., and Davis, C. (2008). Analysis of behavioral constraints and the neuroanatomy of fear to the predator odor trimethylthiazoline: a model for animal phobias. Neurosci. Biobehav. Rev. 32, 1267-1276.

Rosen, J. B., and Schulkin, J. (1998). From normal fear to pathological anxiety. Psychol. Rev. 105, 325-350.

Schulkin, J. (2003). Rethinking Homeostasis. Cambridge, MA: MIT Press.

Schulkin, J., Morgan, M. A., and Rosen, J. B. (2005). A neuroendocrine mechanism for sustaining fear. Trends Neurosci. 28, 629-635.

Sheriff, M. J., Krebs, C. J., and Boonstra, R. (2009). The sensitive hare: sublethal effects of predator stress on reproduction in snowshoe hares. J. Anim. Ecol. 78, 1249-1258.

Sheriff, M. J., Krebs, C. J., and Boonstra, R. (2010). The ghosts of predators past: population cycles and the role of maternal programming under fluctuating predation risk. Ecology 91, 2983-2994.

Silva, A. C., Hee Lee, J., Aoki, I., and Koretsky, A. P. (2004). Manganeseenhanced magnetic resonance imaging (MEMRI): methodological and practical considerations. NMR Biomed. 17, 532-543. doi: 10.1002/ nbm.945

Stam, R. (2007). PTSD and stress sensitisation: a tale of brain and body. Part 2: animal models. Neurosci. Biobehav. Rev. 31, 558-584.

Stankowich, T., and Blumstein, D. T. (2005). Fear in animals: a metaanalysis and review of risk assessment. 
Proc. R. Soc. Lond. B Biol. Sci. 272, 2627-2634.

Staples, L. G., McGregor, I. S., and Hunt, G.E. (2009). Long-lasting FosB/ $\Delta$ FosB immunoreactivity in the rat brain after repeated cat odor exposure. Neurosci. Lett. 462, 157-161.

Takahashi, L. K., Chan, M. M., and Pilar, M.L. (2008). Predator odor fear conditioning: current perspectives and new directions. Neurosci. Biobehav. Rev. 32, 1218-1227.

Travers, M., Clinchy, M., Zanette, L., Boonstra, R., and Williams, T. D. (2010). Indirect predator effects on clutch size and the cost of egg production. Ecol. Lett. 13, 980-988.
Van der Linden, A., Van Camp, N., Ramos-Cabrer, P., and Hoen, M. (2007). Current status of functional MRI on small animals: application to physiology, pathophysiology, and cognition. NMR Biomed. 20, 522-545. doi: $10.1002 / \mathrm{nbm} .1131$

Weaver, I. C. G., Cervoni, N., Champagne, F.A., D'Alessio, A. C., Sharma, S., Seckl, J. R., Dymov, S., Szyf, M., and Meaney, M. J. (2004). Epigenetic programming by maternal behavior. Nat. Neurosci. 7, 847-854.

Yehuda, R., and Bierer, L. M. (2009). The relevance of epigenetics to PTSD: implications for the DSM-V. J. Trauma. Stress 22, 427-434.
Zoumakis, E., Rice, K. C., Gold, P. W., and Chrousos, G. P. (2006). Potential uses of corticotropin-releasing hormone antagonists. Ann. N. Y. Acad. Sci. 1083, 239-251.

Conflict of Interest Statement: The authors declare that the research was conducted in the absence of any commercial or financial relationships that could be construed as a potential conflict of interest.

Received: 15 December 2010; paper pending published: 28 January 2011; accepted: 09 April 2011; published online: 25 April 2011.
Citation: Clinchy M, Schulkin J, Zanette $L Y$, Sheriff MJ, McGowan PO and Boonstra R (2011) The neurological ecology of fear: insights neuroscientists and ecologists have to offer one another. Front. Behav. Neurosci. 5:21. doi: 10.3389/ fnbeh.2011.00021

Copyright (c) 2011 Clinchy, Schulkin, Zanette, Sheriff, McGowan and Boonstra. This is an open-access article subject to a non-exclusive license between the authors and Frontiers Media SA, which permits use, distribution and reproduction in other forums, provided the original authors and source are credited and other Frontiers conditions are complied with. 